Madden-Julian Oscillation (MJO), the El Niño/Southern Oscillation (ENSO), the thermohaline circulation, and Earth's orbital variations are reviewed. External forcing, potentially caused by solar variability, is given an objective description. Finally, statistical explanations are explored: the possibility that it is all "noise," that it is noise with memory or nonlinear resonance, and that it is the result of low order chaos. Only a few cyclicities survive Burroughs' analysis: the annual cycle, the quasibiennial oscillation, the El Niño-Southern Oscillation (ENSO), and perhaps a bidecadal cycle.

I found only a few features of this book with which to quibble. The use of the term "weather" in the title is not quite representative of the subject matter, which is mainly concerned with climate changes on interannual and longer time scales. There are a few subtle referencing errors. Typographical errors (some new, others holdovers from the first edition) are regrettable. I found the observational summary tables $(3.1,4.2)$ difficult to parse and not entirely consistent with the text or my reading of the data. However, the overall point that most cycles are not well defined and appear to come and go, or shift frequencies, over the time period, remains well taken.

Most intriguing to me was Burroughs's suggestion of a chaotic framework for the observations and our predictive failures. He has produced a well-written, clearly illustrated review, which makes an important point. But
Burroughs stops short of fully developing chaos as a paradigm for his review of the extant climatological and paleoclimatological data. I only hope that he has done so to whet our appetites for a companion volume exploring this hypothesis, as was done so well by Paul Ormerod (The Death of Economics, 1994; Butterfly Economics, 1998) for economic and social phenomena. In the meantime, I will recommend this book to colleagues and friends interested in the science of climate change. 囵

Michael N. Evans (mevans@ltrr.arizona. edu) is Assistant Professor, Laboratory of Tree-Ring Research, The University of Arizona, Tucson, USA.

\title{
Changing Sea Levels Effects of Tides, Weather and Climate
}

Written by David Pugh

Cambridge University Press

2004, 280 pages

Hardcover: ISBN 0521825326, \$115 US

Paperback: ISBN 0521532183, \$60 US

\section{REVIEWED BY NICK HARVEY}

Changing Sea Levels: Effects of Tides, Weather and Climate by David Pugh is a welcome addition to the literature, particularly because of the increasing debate over predictions for sea-level rise stimulated by deliberations and re- ports of the Intergovernmental Panel on Climate Change (IPCC). This book is aimed at undergraduate students involved in interdisciplinary studies, although it will also be very useful for a variety of professionals such as coastal planners and engineers.

The book, which arose from Pugh's earlier (1996) volume, Tides, Surges and Mean Sea-Level, has been written in an informative and easy-to-read style in a deliberate attempt to reduce the number of statistics presented. Additional mathematical detail is given in an appendix

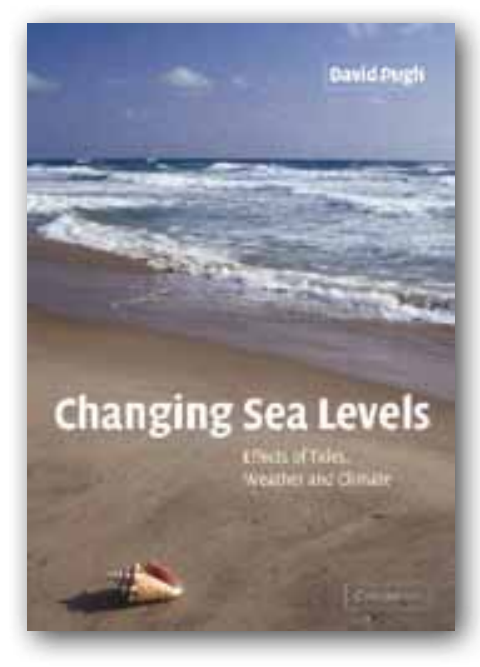

and on a related web site. The book is very well illustrated with clear black and white diagrams and photographs. In addition, eight of the more complex global diagrams have been reproduced in color 
to make their interpretation easier. Overall, this is a very appealing text.

Changing Sea Levels is organized into nine chapters, each of which concludes with a series of questions related to that chapter and a useful guide to further reading on the topic. The first chapter begins by examining how sea level is actually measured. It includes a discussion of direct-measuring instruments, such as tide poles and float gauges; fixed sensors, such as acoustic and pressure sensitive systems; and satellite altimetry. This introductory chapter discusses the advantages, disadvantages, and accuracy of various techniques. It also provides a quality discussion on the use of satellite data, modern GPS technology, and the Global Sea Level Observing System (GLOSS).

Chapters 2 through 5 deal with the science of tidal generation. Chapter 2 examines tidal diversity, the gravitational forces, tidal patterns, and the influence of the geoid. Chapter 3 provides an outline of methods for tidal analysis and prediction, including the use and correction of satellite altimetry data. Chapters 4 and 5 examine tidal dynamics both in the open ocean and near the coast.

Having outlined tidal analysis and interpretation in earlier chapters, Chapter 6 then examines the factors influencing tides such as the weather, wind stress, and the creation of storm surges. Here Pugh provides the reader various regional examples of surge generation, including extra-tropical storms in the North Sea and the tropical cyclone surges in the Bay of Bengal. The chapter concludes by looking at tsunami generation and issues of flood risk and warning systems.

Chapter 7 addresses the topical issue of mean sea level (MSL), which has at- tracted public interest through the debate on global climate change and possible future impacts it can have, such as increasing MSL and coastal flood risk. This chapter examines the nature of the historic tide-gauge record and explains the problems of deriving accurate MSL trends from the record, including annual and inter-annual changes, isostatic adjustment, and changes in water volume. Chapter 7 provides a strong link to the debate on climate-induced MSL rise and reinforces the point that sea-level measurements are "relative" and there is a need to identify the variations within the record in order to obtain data that can be compared between sites. Pugh discusses the importance of land movements due to a wide range of geological influences, but most importantly, the need for global isostatic adjustment of the data. This adjustment results from the fact that the global redistribution of ice and water following the last glacial has produced a differential response from the world's coastlines. This subtle movement, however, is incorporated in tide-gauge data and needs to be removed in order to calculate meaningful MSL trends. Chapter 7 also discusses changes in seawater water volume within the last century.

Chapters 8 and 9 provide a fitting conclusion to the book with a discussion of a more-applied nature. For example, Chapter 8 examines the meaning of return periods and flood risks and various methods of calculating them. It then proceeds to link these risks to the climate-change debate and describe how they may vary depending on scenario. Scenarios include the effect of tidal changes and different weather patterns on coastal impacts. Chapter 8 also provides a very good introduction to responses to changes in flood risk. However, at the end of the Chapter 8, Pugh refers to the Intergovernmental Panel Climate Change (IPCC) Common Methodology as though it provides a tried and tested response strategy. Although there is a need for global cooperation in addressing the issue, this methodology has been criticized as difficult to use and having a lack of applicability for some countries.

Chapter 9 concludes the book with a discussion on the importance of sealevel changes and their influences. It examines tidal inlets and tidal flows, the impact of tides on sediment movements, the importance of tides for mangroves and salt marshes, and the zonal effect of tides on coastal ecology. The final part of this chapter places modern sea level in a geological context of sea-level change over the last 140,000 years and then ends the book on the practical note of legal definitions of tidal boundaries.

In summary, I found this book very informative and easy to read. As both a coastal scientist and a university teacher, I found its style excellent. I am sure this book will have strong appeal as a text for a number of undergraduate disciplinary programs. It will also appeal to the general public and could be particularly useful to coastal planners and engineers. एव
Nick Harvey (nicholas.harvey@adelaide. edu.au) is Professor and Head, Geography and Environmental Studies, The University of Adelaide, South Australia and is currently a Lead Author for the Intergovernmental Panel on Climate Change (Working Group II) Fourth Assessment Report. 